\title{
Dark Triad Traits and Sleep-Related Constructs: An Opinion Piece
}

\author{
Kenneth Graham Drinkwater*, Neil Dagnall and Andrew Denovan \\ Department of Psychology, Faculty of Health, Psychology and Social Care, Manchester Metropolitan University, Manchester, \\ United Kingdom
}

Keywords: lucid dreaming, sleep-related constructs, dark triad traits, personality dimensions, methodological issues

\section{INTRODUCTION}

Good quality sleep is vital to health and psychological functioning (see Steptoe et al., 2008). Indeed, insufficient sleep has a negative effect on chronic disease incidence and development (Perry et al., 2013). Alongside health implications, the investigation of sleep is important because it conceptually informs a range of academic disciplines (neuropsychology, physiology, psychology, etc.). Acknowledgment of these factors has stimulated research, which historically has identified sleep-related dissociative states (nightmares, dreams, etc.), and outlined factors that influence the timing, duration, and quality of sleep.

From a psychological perspective, investigators have placed great emphasis on examining relationships between sleep states, personality factors (e.g., Randler et al., 2017), and related constructs (e.g., creativity). However, relatively few studies have focused on lucid dreaming (LD)

OPEN ACCESS

Edited by:

Roumen Kirov

Institute of Neurobiology (BAS), Bulgaria

Reviewed by:

Serge Brand,

University Psychiatric Clinic

Basel, Switzerland

*Correspondence:

Kenneth Graham Drinkwater k.drinkwater@mmu.ac.uk

Specialty section:

This article was submitted to

Consciousness Research, a section of the journal Frontiers in Psychology

Received: 19 December 2019 Accepted: 02 March 2020 Published: 19 March 2020

Citation:

Drinkwater KG, Dagnall N and Denovan A (2020) Dark Triad Traits and Sleep-Related Constructs: An

Opinion Piece. Front. Psychol. 11:505. doi: 10.3389/fpsyg.2020.00505 (e.g., Schredl et al., 2016).

LD is a distinct behavioral state characterized by awareness of dreaming during sleep, which involves the ability to control dream events, and/or purposefully awaken (Harb et al., 2016). Future individual differences research needs to consider LD since the phenomenon has important implications for models of human cognition. Explicitly, LD provides insights into the nature and constraints of consciousness, particularly the potential for reflective mindfulness (Kahan and LaBerge, 1994). Additionally, LD has useful applications for experiencers (solving waking problems, physical/mental healing, training motor skills, etc.) (Stumbrys and Erlacher, 2016), and possesses potential therapeutic benefits (e.g., reducing nightmare frequency) (Holzinger et al., 2015).

Even fewer studies in the domain of personality and individual differences research have examined relationships between LD and socially aversive traits (Marcus and Zeigler-Hill, 2015). This is an important research gap to bridge as interest in dark traits is ever increasing and related constructs (i.e., Machiavellianism, narcissism and psychopathy) possess characteristics, which are likely to affect lucid dreaming. In this context, the influence of the Dark Triad (DT) personality construct is fundamental (Paulhus and Williams, 2002). The recent emergence of work investigating associations between darker, social malevolent personality traits and variations in sleep-related behavior and states reflects this (e.g., Yang et al., 2019).

From this perspective, the DT is particularly important. The DT refers to three personality dimensions marked by manipulation and callousness: Machiavellianism, subclinical narcissism, and subclinical psychopathy (Jones and Paulhus, 2014). Machiavellianism denotes a calculative attitude encompassing the ability to control others, deception, self-centeredness and immorality. Although, individuals scoring high on Machiavellianism present as charming and impressive, these speciously "attractive" attributes mask propensity to hypocrisy, cynical worldview, and scheming.

Narcissism reflects a clash between grandiose identity and underlying insecurity that manifests as the need for constant ego-reinforcement (Jones and Paulhus, 2014). Several studies report 
the existence of two or more forms of narcissism (Miller et al., 2011). The most prevalent distinction being between grandiose and vulnerable. Grandiose comprises grandiosity, aggression and dominance, whereas vulnerable narcissism reflects a defensive and insecure grandiosity that obfuscates adverse cognitions, perceptions, and emotions (i.e., feelings of inadequacy, incompetence, and negative affect) (Miller et al., 2011).

Psychopathy indexes deficits in affect (i.e., callousness; disregard for others and lack of empathy) and self-control (i.e., impulsivity) (Hare, 1970; Cleckley, 1976; Lykken, 1995). Callousness is typically short-term. Hence, psychopaths lie for immediate rewards, even when this undermines their long-term goals (Paulhus and Williams, 2002). Thus, in the context of psychopathy, callous manipulation combines with immediate tendencies such as thrill seeking and recklessness to prompt related dispositions, and facilitate corresponding behaviors (Hare and Neumann, 2008). Authors often make a distinction between primary and secondary psychopaths. Historically, researchers have often linked primary psychopathy to genetic factors and secondary psychopathy to social factors (Skeem et al., 2007). Primary psychopaths are callous, calculating, manipulative, and deceitful, whereas secondary psychopaths share antisocial behaviors with primary psychopaths, but are remorseful and fearful (Sethi et al., 2018).

\section{INDICATIVE RESEARCH}

To explore further LD and individual differences, investigators need to consider the findings/scope of previous work. This has demonstrated that DT traits can influence sleep-related states/behavior and has produced theoretically important findings. For instance, Jonason et al. (2013) observed a link between "darker" DT elements (Machiavellianism, secondary psychopathy, and exploitive narcissism) and a night specialism (chronotype). This predisposes individuals toward optimal cognitive performance during the hours of darkness.

Additionally, Sabouri et al. (2016) found that Machiavellianism and psychopathy were associated with higher sleep disturbances, increased anxiety sensitivity, and greater intolerance of uncertainty. These outcomes aligned with previous research documenting relationships between negative affect and poor sleep (Whiteside and Lynam, 2001; Brand et al., 2016). Noting this, Sabouri et al. (2016) concluded that the association between DT traits and sleep disturbance arises from unfavorable cognitive-emotional processes. Specifically, rumination, poor coping strategies, and low emotion regulation. Relatedly, Yang et al. (2019) found Machiavellianism was directly associated with poor sleep quality, and indirectly associated via greater anger rumination. Additionally, primary and secondary psychopathy were indirectly associated with poor sleep quality via greater anger rumination. Secondary psychopathy had the strongest direct effect on poor sleep quality among the DT traits.

These findings were congruent with preceding studies reporting relationships between poor sleep, reduced emotion regulation (Brand et al., 2016), and lack of impulse control (Becker, 2014). In this context, LD may reduce negative emotions by allowing the dreamer to take control of the dream.
Knowing that it is possible to govern dream content can facilitate the reduction of adverse affective content. Earlier work suggests that this can reduce distress within nightmares (Gavie and Revonsuo, 2010), and concomitantly lessen nightmare frequency and intensity, leading to better life quality during wakefulness (Soffer-Dudek, 2017).

\section{DISCUSSION}

Although studies examining relationships between sleep-related states and personality traits make important contributions to conceptual understanding of sleep, several methodological issues limit the generalizability of findings. For prospective research on $\mathrm{LD}$ and the $\mathrm{DT}$ to be effective, researchers need to acknowledge these concerns when designing studies, and discussing outcome implications.

A major limitation of previous work is that studies have typically used a cross-sectional method. This is where researchers collect data simultaneously, at one time point and/or within a brief duration (Levin, 2006). The cross-sectional method is criticized because responses represent only a "snapshot" of characteristics associated with the measured outcome at a particular point in time. Consequently, data provides only "estimates" of prevalence within populations. This explains why cross-sectional studies frequently provide limited correlationbased analysis and report weak correlations.

Even when researchers employ sophisticated analytical techniques, causation remains an issue. Particularly, it is difficult to conclude whether sleep-related experience/behavior derives from personality factors or causes enduring behaviors and perceptions. One potential remedy within mediation-based studies is reverse testing, where analysis compares the predicted model against an alternative. This statistically assesses whether the indirect effect of independent variable $(\mathrm{X})$ on the dependent variable $(\mathrm{Y})$ via the intervening factor $(\mathrm{M})$ is significantly different from zero. Despite providing some indication of causality this approach is not always successful (Lemmer and Gollwitzer, 2017).

Another issue with cross-sectional studies is common method variance (CMV) (Chang et al., 2010). This denotes shared variance arising from the method used, rather than the constructs observed (Podsakoff et al., 2003). CMV creates false internal consistency, correlation arising from common context. This manifests as the tendency to respond consistently to unrelated items. Hence, one index of sleep may influence scores on another, or responses on DT factors. This is a major concern within sleeprelated research because observed relationships are often weak, and CMV can inflate correlations (Lindell and Whitney, 2001). Thus, without safeguards there is an increased possibility of type 1 error. Studies can reduce the dangers of CMV by creating psychological distance between constructs, and by employing instructions that reduce social desirability effects and evaluation apprehension (Podsakoff et al., 2003). To guard against CMV, studies investigating relationships between LD and the DT should employ protocols that emphasize differences between constructs and response scales.

Furthermore, while repeated cross-sectional studies can enhance the reliability of findings, the cross-sectional approach 
still fails to control for the effects of unaccounted factors. One such variable, which investigators have frequently included in sleep-related research, is mental toughness. Mental toughness is a generic term that denotes enabling psychological resources that promote positive mental health and performance across a range of achievement contexts (Dagnall et al., 2019; Drinkwater et al., 2019). Noting this generality, Gucciardi (2017) defined mental toughness as "a state-like psychological resource that is purposeful, flexible, and efficient in nature for the enactment and maintenance of goal-directed pursuits" (p. 18).

Intervening constructs that influence relationships between sleep-related states and personality factors are problematic because they produce complex effects. For instance, greater mental toughness is associated with better sleep quality, shorter sleep onset latency, fewer awakenings, longer sleep duration, and reduced sleep complaints (Brand et al., 2014a,b). Additionally, higher levels of mental toughness correlate with positive psychological health outcomes (Gerber et al., 2018). Pertinently, mental toughness influences also DT traits. Particularly, Papageorgiou et al. (2019) observed that the subclinical narcissism to mental toughness pathway in their model predicted lower levels of psychiatric symptoms. Moreover, Papageorgiou et al. (2017) reported that mental toughness facilitated the development of the adaptive aspects of narcissism (e.g., coping behaviors).

Noting these factors, subsequent work on the relationship between LD and the DT should control for mental toughness, consider the role of moderating/mediating factors generally, and examine effects over extended periods using multiple time points. Although, multiple time point studies are prone to logistical difficulties (i.e., recruitment and retention) and expensive in terms of time and cost, they provide a nuanced understanding of how personality traits effect sleep-related measures over time (relationship stability).

Regarding LD, the use of standardized definitions and measurement indexes is vital to cross study comparisons. In the case of classifications, there exists significant variation across studies. For instance, while several use the Schredl and Erlacher (2004) conceptualization (e.g., Denis and Poerio, 2017), others employ different wording (e.g., Sestir et al., 2019), or have devised alternative measures (Aviram and Soffer-Dudek, 2018; the Frequency and Intensity Lucid Dream questionnaire, FILD).

Moreover, studies also index different aspects of LD. For instance, alongside prevalence and frequency (see Snyder and Gackenbach, 1988) papers often include measures of

\section{REFERENCES}

Aviram, L., and Soffer-Dudek, N. (2018). Lucid dreaming: intensity, but not frequency, is inversely related to psychopathology. Front. Psychol. 9:384. doi: 10.3389/fpsyg.2018.00384

Becker, S. P. (2014). External validity of children's self-reported sleep functioning: associations with academic, social, and behavioral adjustment. Sleep Med. 15, 1094-1100. doi: 10.1016/j.sleep.2014.06.001

Brand, S., Gerber, M., Kalak, N., Kirov, R., Lemola, S., Clough, P. J., et al. (2014a). Adolescents with greater mental toughness show higher sleep efficiency, more deep sleep and fewer awakenings after sleep onset. J. Adolesc. Health 54, 109-113. doi: 10.1016/j.jadohealth.2013.07.017 control and dream environment manipulation (Stumbrys and Erlacher, 2017). To ensure comparability it is important that researchers examining $\mathrm{LD}$ agree on standard operationalizations and indices. This is especially important when prior research is relatively limited as outcome variations resulting from different measurement instruments can produce conceptual fragmentation. This problem is not unique to LD. Indeed, work investigating other sleep-related states/behaviors draws on a range of measurement tools and indexes a variety of indicators. For example, there are multiple scales used to assess insomnia.

A further issue is that sleep-related studies regularly use selfreport. Critics question the validity and accuracy of these because they assess psychological processes indirectly by drawing upon metacognitive insight and recall (Lance and Vandenberg, 2009). This leaves self-report measures vulnerable to subjective bias. Hence, it is advisable to corroborate LD self-report findings with objective indices.

Researchers examining the influence of the on sleep-related states/behavior need also to consider the role of DT sub-factors. Illustratively, Jonason et al. (2013) reported that only exploitive narcissism was associated with night specialism. Moreover, primary and secondary psychopathy have different relationships with anxiety-related constructs. Primary correlates negatively, whereas secondary is positively associated. This suggests that effects will vary as a function of DT factor type.

Finally, future studies need to establish cross-cultural, age and gender invariance. This will help to counter potential measurement bias. In the case of the Short Dark Triad (SD3, Jones and Paulhus, 2014), researchers report the instrument is invariant for language and culture (Pechorro et al., 2019). It is essential that investigators similarly evaluate sleeprelated measures.

Addressing these issues will ensure that future research examining relationships between the DT and sleep-related measures generates more robust, convincing findings.

\section{AUTHOR CONTRIBUTIONS}

$\mathrm{ND}$ and $\mathrm{AD}$ : article development and composition. KD: draft review and creative oversight.

\section{ACKNOWLEDGMENTS}

Thanks to the reviewer for helpful, constructive, and insightful comments.

Brand, S., Gerber, M., Kalak, N., Kirov, R., Lemola, S., Clough, P. J., et al. (2014b). "Sleep well, our tough heroes!"-in adolescence, greater mental toughness is related to better sleep schedules. Behav. Sleep Med. 12, 444-454. doi: 10.1080/15402002.2013.825839

Brand, S., Kirov, R., Kalak, N., Gerber, M., Schmidt, N. B., Lemola, S., et al. (2016). Poor sleep is related to lower emotional competence among adolescents. Behav. Sleep Med. 14, 602-614. doi: 10.1080/15402002.2015.10 48450

Chang, S. J., van Witteloostuijn, A., and Eden, L. (2010). From the editors: common method variance in international business research. J. Int. Bus. Stud. 41, 178-184. doi: 10.1057/jibs.2009.88

Cleckley, H. (1976). The Mask of Sanity, 5th Edn. St. Louis, MO: Mosby. 
Dagnall, N., Denovan, A., Papageorgiou, K. A., Clough, P. J., Parker, A., and Drinkwater, K. G. (2019). Psychometric assessment of shortened Mental Toughness Questionnaires (MTQ): factor structure of the MTQ-18 and the MTQ-10. Front. Psychol. 10:1933. doi: 10.3389/fpsyg.2019.01933

Denis, D., and Poerio, G. L. (2017). Terror and bliss? Commonalities and distinctions between sleep paralysis, lucid dreaming, and their associations with waking life experiences. J. Sleep Res. 26, 38-47. doi: 10.1111/jsr.12441

Drinkwater, K., Dagnall, N., Denovan, A., and Parker, A. (2019). The moderating effect of mental toughness: perception of risk and belief in the paranormal. Psychol. Rep. 122, 268-287. doi: 10.1177/0033294118756600

Gavie, J. E., and Revonsuo, A. (2010). The future of lucid dreaming treatment. Int. J. Dream Res. 3, 13-15. doi: 10.11588/ijodr.2010.1.591

Gerber, M., Best, S., Meerstetter, F., Walter, M., Ludyga, S., Brand, S., et al. (2018). Effects of stress and mental toughness on burnout and depressive symptoms: a prospective study with young elite athletes. J. Sci. Med. Sport 21, 1200-1205. doi: $10.1016 /$ j.jsams.2018.05.018

Gucciardi, D. F. (2017). Mental toughness: progress and prospects. Curr. Opin. Psychol. 16, 17-23. doi: 10.1016/j.copsyc.2017.03.010

Harb, G. C., Brownlow, J. A., and Ross, R. J. (2016). Posttraumatic nightmares and imagery rehearsal: the possible role of lucid dreaming. Dreaming 26, 238-249. doi: $10.1037 / \mathrm{drm} 0000030$

Hare, R. D. (1970). Psychopathy: Theory Research, and Implications for Society. New York, NY: Wiley.

Hare, R. D., and Neumann, C. S. (2008). Psychopathy as a clinical and empirical construct. Ann. Rev. Clin. Psychol. 4, 217-246. doi: 10.1146/annurev.clinpsy.3.022806.091452

Holzinger, B., Klösch, G., and Saletu, B. (2015). Studies with lucid dreaming as add-on therapy to gestalt therapy. Acta Neurol. Scand. 131, 355-363. doi: 10.1111/ane.12362

Jonason, P. K., Jones, A., and Lyons, M. (2013). Creatures of the night: chronotypes and the dark triad traits. Pers. Individ. Dif. 55, 538-541. doi: 10.1016/j.paid.2013.05.001

Jones, D. N., and Paulhus, D. L. (2014). Introducing the short dark triad (SD3) a brief measure of dark personality traits. Assessment 21, 28-41. doi: $10.1177 / 1073191113514105$

Kahan, T. L., and LaBerge, S. (1994). Lucid dreaming as metacognition: implications for cognitive science. Conscious. Cogn. 3, 246-264. doi: 10.1006/ccog.1994.1014

Lance, C., and Vandenberg, R. (Eds.). (2009). "Statistical and methodological myths and urban legends: doctrine, verity and fable in the organizational and social sciences," in International Journal of Research in Marketing, Vol. 26 (New York, NY: Routledge), 332-344.

Lemmer, G., and Gollwitzer, M. (2017). The "true" indirect effect won't (always) stand up: when and why reverse mediation testing fails. J. Exp. Soc. Psychol. 69, 144-149. doi: 10.1016/j.jesp.2016.05.002

Levin, K. A. (2006). Study design III: cross-sectional studies. Evid. Based Dent. 7, 24-25. doi: 10.1038/sj.ebd.6400375

Lindell, M. K., and Whitney, D. J. (2001). Accounting for common method variance in cross-sectional research designs. J. Appl. Psychol. 86, 114-121. doi: 10.1037/0021-9010.86.1.114

Lykken, D. T. (1995). The Antisocial Personalities. Hillsdale, NJ: Lawrence Erlbaum.

Marcus, D. K., and Zeigler-Hill, V. (2015). A big tent of dark personality traits. Soc. Personal. Psychol. Compass. 9, 434-446. doi: 10.1111/spc3.12185

Miller, J. D., Hoffman, B. J., Gaughan, E. T., Gentile, B., Maples, J., and Campbell, W. K. (2011). Grandiose and vulnerable narcissism: a nomological network analysis. J. Pers. 79, 1013-1042. doi: 10.1111/j.1467-6494.2010.00711.x

Papageorgiou, K. A., Denovan, A., and Dagnall, N. (2019). The positive effect of narcissism on depressive symptoms through mental toughness: narcissism may be a dark trait but it does help with seeing the world less grey. Eur. Psychiatry 55, 74-79. doi: 10.1016/j.eurpsy.2018.10.002

Papageorgiou, K. A., Wong, B., and Clough, P. J. (2017). Beyond good and evil: exploring the mediating role of mental toughness on the dark triad of personality traits. Pers. Individ. Dif. 119, 19-23. doi: 10.1016/j.paid.2017.06.031

Paulhus, D. L., and Williams, K. M. (2002). The dark triad of personality: narcissism, machiavellianism, and psychopathy. J. Res. Pers. 36, 556-563. doi: 10.1016/S0092-6566(02)00505-6
Pechorro, P., Caramelo, V., Oliveira, J. P., Nunes, C., Curtis, S. R., and Jones, D. N. (2019). The Short Dark Triad (SD3): adaptation and psychometrics among at-risk male and female youths. Deviant Behav. 40, 273-286. doi: 10.1080/01639625.2017.1421120

Perry, G. S., Patil, S. P., and Presley-Cantrell, L. R. (2013). Raising awareness of sleep as a healthy behavior. Prev. Chronic Dis. 10:E133. doi: $10.5888 /$ pcd10.130081

Podsakoff, P. M., MacKenzie, S. B., Lee, J. Y., and Podsakoff, N. P. (2003). Common method biases in behavioral research: a critical review of the literature and recommended remedies. J. Appl. Psychol. 88, 879-903. doi: 10.1037/0021-9010.88.5.879

Randler, C., Schredl, M., and Göritz, A. S. (2017). Chronotype, sleep behavior, and the big five personality factors. SAGE Open 7:2158244017728321. doi: $10.1177 / 2158244017728321$

Sabouri, S., Gerber, M., Lemola, S., Becker, S. P., Shamsi, M., Shakouri, Z., et al. (2016). Examining dark triad traits in relation to sleep disturbances, anxiety sensitivity and intolerance of uncertainty in young adults. Compr. Psychiatry 68, 103-110. doi: 10.1016/j.comppsych.2016.03.012

Schredl, M., and Erlacher, D. (2004). Lucid dreaming frequency and personality. Pers. Individ. Dif. 37, 1463-1473. doi: 10.1016/j.paid.2004.02.003

Schredl, M., Henley-Einion, J., and Blagrove, M. (2016). Lucid dreaming and personality in children/adolescents and adults: the UK library study. Int. J. Dream Res. 9, 75-78. doi: 10.11588/ijodr.2016.1.26454

Sestir, M., Tai, M., and Peszka, J. (2019). Relationships between video game play factors and frequency of lucid and control dreaming experiences. Dreaming 29, 127-143. doi: 10.1037/drm0000102

Sethi, A., McCrory, E., Puetz, V., Hoffmann, F., Knodt, A. R., Radtke, S. R., et al. (2018). Primary and secondary variants of psychopathy in a volunteer sample are associated with different neurocognitive mechanisms. Biol. Psychiatry Cogn. Neurosci. Neuroimaging 3, 1013-1021. doi: 10.1016/j.bpsc.2018.04.002

Skeem, J., Johansson, P., Andershed, H., Kerr, M., and Louden, J. E. (2007). Two subtypes of psychopathic violent offenders that parallel primary and secondary variants. J. Abnorm. Psychol. 116, 395-409. doi: 10.1037/0021-843X.116.2.395

Snyder, T. J., and Gackenbach, J. (1988). "Individual differences associated with lucid dreaming," in Conscious Mind, Sleeping Brain: Perspectives on Lucid Dreaming, eds J. Gackenbach and S. LaBerge (New York, NY: Plenum), 221260.

Soffer-Dudek, N. (2017). Arousal in nocturnal consciousness: how dreamand sleep-experiences may inform us of poor sleep quality, stress, and psychopathology. Front. Psychol. 8:733. doi: 10.3389/fpsyg.2017.00733

Steptoe, A., O’Donnell, K., Marmot, M., and Wardle, J. (2008). Positive affect, psychological well-being, and good sleep. J. Psychosom. Res. 64, 409-415. doi: 10.1016/j.jpsychores.2007.11.008

Stumbrys, T., and Erlacher, D. (2016). Applications of lucid dreams and their effects on the mood upon awakening. Int. J. Dream Res. 9, 146-150. doi: 10.11588/ijodr.2016.2.33114

Stumbrys, T., and Erlacher, D. (2017). Mindfulness and lucid dream frequency predicts the ability to control lucid dreams. Imagin. Cogn. Pers. 36, 229-239. doi: $10.1177 / 0276236616683388$

Whiteside, S. P., and Lynam, D. R. (2001). The five factor model and impulsivity: using a structural model of personality to understand impulsivity. Pers. Individ. Dif. 30, 669-689. doi: 10.1016/S0191-8869(00)00064-7

Yang, M., Zhu, X., Sai, X., Zhao, F., Wu, H., and Geng, Y. (2019). The dark triad and sleep quality: mediating role of anger rumination. Pers. Individ. Dif. 151:109484. doi: 10.1016/j.paid.2019.06.027

Conflict of Interest: The authors declare that the research was conducted in the absence of any commercial or financial relationships that could be construed as a potential conflict of interest.

Copyright (c) 2020 Drinkwater, Dagnall and Denovan. This is an open-access article distributed under the terms of the Creative Commons Attribution License (CC BY). The use, distribution or reproduction in other forums is permitted, provided the original author(s) and the copyright owner(s) are credited and that the original publication in this journal is cited, in accordance with accepted academic practice. No use, distribution or reproduction is permitted which does not comply with these terms. 